\title{
Efficient vertical transport of black carbon in the planetary boundary layer
}

Dantong Liu ${ }^{1 *}$, Kang $\mathrm{Hu}^{1}$, Delong Zhao ${ }^{2}$, Shuo Ding ${ }^{1}$, Yunfei $\mathrm{Wu}^{3}$, Chang $\mathrm{Zhou}^{3}$, Chenjie $\mathrm{Yu}^{4}$, Ping $\mathrm{Tian}^{2}$, Quan $\mathrm{Liu}^{2}, \mathrm{Kai} \mathrm{Bi}^{2}$, Yangzhou $\mathrm{Wu}^{1}$, Bo $\mathrm{Hu}^{4}$, Dongsheng $\mathrm{Ji}^{4}$, 5 Shaofei Kong ${ }^{6}$, Bin Ouyang ${ }^{7}$, Hui $\mathrm{He}^{2}$, Mengyu Huang ${ }^{2}$, Deping Ding ${ }^{2}$

${ }^{1}$ Department of Atmospheric Sciences, School of Earth Sciences, Zhejiang University, Hangzhou, Zhejiang, China.

${ }^{2}$ Beijing Weather Modification Office, Beijing, China.

${ }^{3}$ Key Laboratory of Regional Climate-Environment for Temperate East Asia (RCE-TEA), Institute of Atmospheric Physics, Chinese Academy of Sciences, Beijing 100029, China.

${ }^{4}$ Centre for Atmospheric Sciences, School of Earth and Environmental Sciences, University of Manchester, Manchester M13 9PL, UK.

${ }^{5}$ State Key Laboratory of Atmospheric Boundary Layer Physics and Atmospheric Chemistry, Institute of Atmospheric Physics, Chinese Academy of Science, Beijing, China.

${ }^{6}$ Department of Atmospheric Sciences, School of Environmental Studies, China University of Geosciences, Wuhan, China.

${ }^{7}$ Lancaster Environment Centre, Library Avenue, Lancaster University, Lancaster, LA1 4YQ, UK.

Corresponds to: dantongliu@zju.edu.cn

Key Points:

- Simultaneous measurements at both surface and top of boundary layer were performed for one month.

- $\mathrm{BC}$ was transported efficiently to the top of PBL however not for other more volatile aerosols.

30 - Higher BC mass fraction over the top of boundary layer with lowered singlescattering albedo by 0.06 . 


\begin{abstract}
Vertical distribution of black carbon (BC) determines the layer where its heating impacts exert. This study presents continuous and simultaneous measurements at surface, and on a mountain site above the wintertime planetary boundary layer influenced by uplifted surface anthropogenic emissions. BC was observed efficiently transported upwards by daytime convective mixing. However, this vertical transport was less for other particulate masses. An about two-folds higher BC mass fraction was thus present at mountain than surface, hereby a lowered single-scattering albedo (SSA) by 0.06 . This may be caused by the evaporative loss of condensed semi-volatile materials, prevailing the secondary particulate formation, in a cleaner environment containing less precursors. The elevated BC mass corresponded with the most intensive solar radiation at midday, wielding more heating impacts over the PBL. This phenomenon may apply to other remote regions where a reduced SSA will introduce more positive radiative effects.
\end{abstract}

Key words: Black carbon, vertical transport, convective mixing, single-scattering albedo 


\section{Plain Language Summary}

Black carbon is strongly light-absorbing and its heating impacts in disturbing the stability of atmosphere depends on its location in the atmospheric column, thus to understand its vertical distribution and transport mechanism is important. This study conducted simultaneous measurements at both sites on the surface and an elevated mountain site influenced by surface sources. We found BC can be efficiently and vertically transported to the mountain site but not for the other more volatile substances. This is because a less secondary formation (due to lack of gas precursor) and some repartition process on the particle (back to the gas phase), may have led to a higher BC mass fraction in cleaner environment. This means in some remote places with less gasprecursor present, $\mathrm{BC}$ may still reach and result in a high mass fraction, leading to more positive radiative effect. 


\section{Background}

Black carbon (BC), as a strong shortwave absorber of solar radiation, may exert important heating impacts to the surrounding atmosphere, especially when high concentration at the regions with intensive emissions [T. C. Bond et al., 2013; Ramanathan and Carmichael, 2008]. For the polluted planetary boundary layer (PBL) highly influenced by anthropogenic emissions, the vertical distribution of $\mathrm{BC}$, in terms of mass loading and absorption capacity, essentially determine to what extent BC absorbs the layer where it locates. This will result in even sometimes contrast consequent impacts on the dynamics of PBL, for example, the heating capacity with either enhance or decrease the temperature inversion, by heating the layer above or below the target atmospheric column. An enhanced temperature inversion will depress the development of the PBL [A Ding et al., 2016; Zhao et al., 2020], while the opposite is for heating at a lower altitude [Y Zhang et al., 2019]. Consistently, the so-called semidirect effect as caused by $\mathrm{BC}$ absorption, may lead to contrast impacts on the cloud physics: a BC layer above the cloud can inhibit cloud development while the layer below cloud may introduce more convection [Koch and Genio, 2010]. This emphasizes the importance in understanding the vertical distribution of BC in the PBL. In addition, the abundance of $\mathrm{BC}$ relative to other aerosols, or the fraction of $\mathrm{BC}$ constituting the aerosol ensemble, importantly modulates the single-scattering albedo (SSA), hereby determining the direction of radiative forcing impacts [Hansen et al., 1981; Takemura et al., 2002].

The vertical distributions of BC and other aerosols in the polluted PBL depend on their transport, removal and evolution of properties since emission, which is also controlled by atmospheric dynamics of PBL, and usually shows apparent diurnal features. A more heated ground surface in the daytime will lead to a stronger upwards transport of pollutants in the PBL through convective mixing (CM) [Garratt, 1994]. Comprehensive vertical profiles of $\mathrm{BC}$ and optical properties have been investigated recently over the polluted eastern China [Ding et al., 2019; Hu et al., 2020; Dantong Liu et al., 2019a]. However, because aircraft measurement is limited on the temporal coverage, the diurnal variation of vertical distributions of pollutants is not able to be continuously monitored, 
in order to reflect the evolution mechanism more generically during their vertical transport in the PBL.

This study for the first time characterized the detailed properties of $\mathrm{BC}$ at both mountain $(\mathrm{h}=1344 \mathrm{~m})$ and surface $(\mathrm{h}=50 \mathrm{~m})$ sites, with mountain site influenced by the surface anthropogenic emissions [Chen et al., 2009], by simultaneous and continuous measurements using advanced instrumentations at both sites (Fig, 1a). This provides diurnal distributions of pollutants at surface and the top of PBL at the same time, revealing the high time-resolution evolution mechanism of pollutants in the PBL.

\section{EXPERIMENTAL AND METHODS}

\subsection{Experimental site and air mass history}

We used two stations locating at different altitudes to perform simultaneous measurements during wintertime 2019 (Fig. 1a). The surface station (the Institute of Atmospheric Physics, Chinese Academy of Science, IAP, 3958'28’'N, 116 22'16”E, $50 \mathrm{~m}$ a.s.1., shown as cross marker in Fig. 1b) represents the urban environment in Beijing (on the northern part of the North China Plain) influenced by intense surface anthropogenic emissions; the mountain station (Haituo mountain, $115.78^{\circ} \mathrm{E}, 40.52^{\circ} \mathrm{N}$, 1344 m a.s.1., star marker in Fig. 1c) locates in the northwest Beijing area, which is connected to the continental plateau extended to the west.

Lagrangian air pollution dispersion model of Numerical Atmospheric dispersion Modeling Environment (NAME) [Jones et al., 2007] is used to compute particle concentrations by Monte Carlo methods, following 3D trajectories of plume parcels. The meteorological data source uses the global configuration of UK Met Office's Unified Model. This model releases tracer particles at a nominal rate of $1 \mathrm{~g} \mathrm{~s}^{-1}$, with a maximum travel time of 24 hours in backward mode from target site as set in this study, and the integrated time was recorded on a $0.25^{\circ} \times 0.25^{\circ}$ horizontal grid from 0 to $1000 \mathrm{~m}$ above the ground, aggregating over all particles for a given release period. Fig. $1 \mathrm{~b}$ and c shows two typical examples of NAME outputs, the color indicates the flux of particle in each grid. The planetary boundary layer height (PBLH) is also calculated using the meteorology field of NAME. 
The potential source contribution of particle concentration at the receptor site is investigated by segregating the region where the backward air masses had passed over as four parts (Fig. 1b): local $\left(38.85-41^{\circ} \mathrm{N}, 115-117^{\circ} \mathrm{E}\right)$ which is an square area around central Beijing and includes the plain regions at the south and east of the mountain site, West (the southern plateau region at $34-41^{\circ} \mathrm{N}, 108-115^{\circ} \mathrm{E}$ ), North (the northern plateau region at $41-43^{\circ} \mathrm{N}, 108-121^{\circ} \mathrm{E}$ ), and South (the southern plain more distant from central Beijing at $34-38.85^{\circ} \mathrm{N}, 115-120^{\circ} \mathrm{E}$ ). The particle flux is integrated in each segregated region, and contributions of each air mass fractions could be obtained (Fig. 2d). Note that the local air mass has accounted for the location of the mountain site, which indicates the influence of local surface emission from urban Beijing.

Local air mass fraction showed clear diurnal pattern with highest fraction around midday (11:00-14:00) contributing more than 40\% of the received air mass (Fig. 1d). Consistently, the PBLH was highest during the time of the day because of the strong radiative heating [Guo et al., 2019], when PBL was fully developed and surface emissions could be vertically transported through convective mixing (CM). The PBLH and local air mass fraction from dispersion model showed consistent diurnal pattern (Fig. 1d). In such way the air mass mostly influenced by the intensive surface emission in the lower-level plain region (Fig. S1a) is identified, but not excluding some possible horizontal transport within the PBL. Certain periods with air mass continuously influenced by westerly air mass (shaded in Fig. 2), are defined as regional advection (RA) [Jinlong, 2002; Streets et al., 2007; Tian et al., 2019], as Fig. 1c shows. These air masses advected pollutants from the polluted southern plateau region according to the emission inventory [M Li et al., 2017] (Fig. S1a). Note that RA period was also influenced by the persistent convective mixing of surface sources around midday (higher local mass fraction), however being combined with additional sources from other regions besides surface emission.

The precipitation removal of $\mathrm{BC}$ is considered to be minor in this study, because the observable accumulated precipitation (integrated along the backtrajectory from NAME model) only lasted for 6 hours during the entire experimental period (Fig. 2a). 


\subsection{Measurements}

BC particle properties were characterized using the single particle soot photometer (SP2, DMT Inc.) at both sites. Aquadag standard (Acheson Inc., USA) was used to calibrate the incandescence signal of each SP2 and a factor of 0.75 was applied to correct for ambient BC [Laborde et al., 2012]. The SP2 scattering channel was calibrated by using mono-dispersed polystyrene latex spheres (PSL), showing a $\pm 3 \%$ laser power performance of the SP2 during the study period. The BC core diameter $\left(\mathrm{D}_{\mathrm{c}}\right)$ was derived from the measured BC mass and an assumed BC density of $1.8 \mathrm{~g} \mathrm{~cm}^{-3}$ [Tami C Bond et al., 2006]. The mass median diameter (MMD) is derived from the $\mathrm{D}_{\mathrm{c}}$ distribution below and above which the $\mathrm{rBC}$ mass is equal. Scattering signal for each BC-containing particle and core size are input to Mie lookup table to obtain the coated particle diameter $\left(D_{p}\right)\left[\right.$ D. Liu et al., 2014; Taylor et al., 2015]. The relative bulk coating thickness $\left(D_{p} / D_{c}\right)$ was calculated as the cubic root of the ratio of total coated BC volume divided by total uncoated rBC volume [D. Liu et al., 2014]:

$170 \quad \frac{D_{p}}{D_{c}}=\sqrt[3]{\frac{\sum_{i} D_{p, i}^{3}}{\sum_{i} D_{c, i}^{3}}}$,

where $D_{p, i}$ and $D_{c, i}$ indicate the coated and uncoated diameter for the $i^{\text {th }}$ single $B C$ particle, respectively. The mass-weighted absorption cross section MAC $\left(\mathrm{m}^{2} \cdot \mathrm{g}^{-1}\right)$ could be obtained using this measured uncoated and coated BC sizes [Hu et al., 2020; Dantong Liu et al., 2017]. By multiplying the $\mathrm{rBC}$ mass concentration $\left(\mu \mathrm{g} \cdot \mathrm{m}^{-3}\right)$ and

175 MAC at each size, after integration to get the absorption coefficient $\mathrm{k}_{\text {abs }}$ (in $\mathrm{Mm}^{-1}$ ) throughout all sizes:

$k_{a b s}=\sum_{i} \operatorname{MAC}\left(D_{p, i}, D_{c, i}\right) m\left(\log D_{c, i}\right) \Delta \log D_{c, i}$,

$\mathrm{m}\left(\log \mathrm{D}_{\mathrm{c}, \mathrm{i}}\right)$ is the $\mathrm{BC}$ mass concentration at each $\mathrm{D}_{\mathrm{c}}$ bin.

Size distribution of all aerosols was measured by a Scanning Mobility Particle Size

180 (SMPS, TSI Inc. Model 3936) at 15-650nm. The effective diameter ( $\mathrm{D}_{\text {eff }}$ is calculated from the size distribution as the third moment divided by the second moment at all sizes $\left(D_{e f f}=\sum D_{i}^{3} / \sum D_{i}^{2}\right)$. For both sites, the total particulate mass (PM) was derived from the SMPS size distribution by assuming a mean particle density of $1.45 \mathrm{~g} \mathrm{~cm}^{-3}[\mathrm{Hu}$ et 
al., 2020], as this gives the best closure with the mass concentration measured by the AMS and SP2 (slope=0.99, Fig. S3). The non-refractory submicron aerosol species at both sites were simultaneously measured using the Aerodyne high-resolution time-offlight AMS (HR-ToF-AMS) [Canagaratna et al., 2007], including sulfate $\left(\mathrm{SO}_{4}{ }^{2-}\right)$, nitrate $\left(\mathrm{NO}_{3}{ }^{-}\right)$, organic aerosol $(\mathrm{OA})$, ammonium $\left(\mathrm{NH}_{4}^{+}\right)$, and chloride $\left(\mathrm{Chl}^{-}\right)$. Both instruments were calibrated before and after the experiment, using monodispersed ammonium nitrate aerosol for ionization efficiency [Jayne et al., 2000], and applied a collection efficiency correction following the principle developed previously [Middlebrook et al., 2012].

All aerosol measurements were performed downstream of a $\mathrm{PM}_{2.5}$ impactor (BGI SCC1.829), and were dried by a Nafion tube before being measured by instruments.

195 CO was measured by a CO Analyzer (Model 48i, Thermo Scientific), which was calibrated by standard gas at multiple concentrations before and after the experiment. The meteorological parameters, including wind speed, wind direction, air temperature and relative humidity, were measured with the miniature atmospheric environment monitoring station (Cambri Inc.), as shown in Fig. S2.

\subsection{Heating rate of $\mathrm{BC}$}

Mie calculation [Bohren and Huffman, 2008] was used to calculate the scattering crosssection $\sigma_{\mathrm{sc}}\left(\mu \mathrm{m}^{2}\right)$ of particle at all sizes by assuming a refractive index (RI) of $1.48+0 \mathrm{i}$ [P Liu et al., 2009] (using a positive imaginary RI by considering BC mass fraction only had minor influence of total scattering $<3 \%$ ), and then multiplying the concentration at each size bin, and integration to give the scattering coefficient $\mathrm{k}_{\text {sca }}$ $\left(\mathrm{Mm}^{-1}\right)$ in that time window:

$k_{s c a}=\sum_{i} \sigma_{s c}\left(D_{i}\right) n\left(\log D_{i}\right) \Delta \log D_{i}$,

where $\mathrm{n}\left(\log \mathrm{D}_{\mathrm{i}}\right)$ represents the particle number concentration at the $\mathrm{i}^{\text {th }}$ size bin.

210 The extinction coefficient is obtained by summing up the $\mathrm{k}_{\mathrm{sca}}$ and $\mathrm{k}_{\mathrm{abs}}$. The aerosol optical depth (AOD) and asymmetry parameter $(g)$ is obtained using the calculated extinction and the backscattering fraction respectively, as described in our previous study [Hu et al., 2020]. Single-scattering albedo (SSA) is calculated as the scattering 
coefficient divided by extinction coefficient.

215 All AOD, $g$ and SSA in real time are calculated at both surface and mountain sites. Hereinafter, an exponential decay function is applied to reconstruct the vertical profile of all parameters [P Liu et al., 2009; Zhao et al., 2019] through this simultaneous measurements at $\mathrm{h}=50 \mathrm{~m}$ and $1344 \mathrm{~m}$, expressed as:

$C(h)=C_{0} e^{-\frac{h}{h_{s}}}$

where $\mathrm{C}_{0}$ indicates the surface observation data and the $C(\mathrm{~h})$ represents the value at height $\mathrm{h}(\mathrm{h}=50 \mathrm{~m}$ and $1344 \mathrm{~m}$ are inputs here $), \mathrm{h}_{\mathrm{s}}$ is gradient index describing the trend of vertical profile, with higher $h_{s}$ indicating a lower vertical gradient. This model has been widely used in previous radiative transfer calculation [Guleria et al., 2014; Srivastava et al., 2012], only using ground surface measurement as constraint. Our twopoints approach here greatly increases the accuracy in profiling the vertical distribution of measured parameters, and is able to successfully capture the diurnal variation of profile patterns (shown in Fig. S6). This reconstructed profile of AOD, SSA and $g$ is further used for radiative transfer calculation.

The actinic flux $\left(\mathrm{F}_{\mathrm{ac}}\right.$, in $\left.\mathrm{W} \cdot \mathrm{m}^{-2}\right)$ at wavelengths $250-2550 \mathrm{~nm}$ were calculated by using Discrete Ordinate Radiative Transfer solvers (DISORT) module in pseudospherical version [Emde et al., 2016]. The model input parameters are summarized in Table S1. The absorbing power of $\mathrm{BC}\left(\mathrm{P}_{\mathrm{abs}}\right.$, in $\left.\mathrm{W} \mathrm{m}^{-3}\right)$ is calculated by multiplying the absorption coefficient and actinic flux, integrating at wavelengths:

$$
P_{a b s}=\int_{\lambda=250 \mathrm{~nm}}^{2550 \mathrm{~nm}} k_{a b}(\lambda) \times F_{a c}(\lambda) d \lambda,
$$

235 The ambient heating rate resulting from $\mathrm{BC}$ absorption $\left(\mathrm{H}_{\mathrm{BC}}\right.$, in $\left.\mathrm{K} \mathrm{day}^{-1}\right)$ is calculated from the absorbing power divided by the air heat capacity:

$H_{B C}=P_{a b s} /\left(C_{a i r} \times \rho_{\text {air }}\right)$,

where $\mathrm{C}_{\text {air }}$ and $\rho_{\text {air }}$ is the heat capacity and density of air.

\section{RESULTS AND DISCUSSION}

\subsection{Efficient upward transport of $B C$}

As the temporal evolution (Fig. 2a) shows, for all the days during the experimental 
period, rBC mass on the mountain exhibited an equivalent level only in the midday compared to that on the surface. During the regional transport period which was dominated by horizontal advection, the equivalent $\mathrm{rBC}$ mass between mountain and surface lasted for a longer time because of the influence of regionally transported air mass at both sites. Fig. 2e clearly showed that the surface concentration of BC was mainly controlled by the development of PBL: a more developed PBL in the daytime (peaking in the midday) diluted the concentration, whereas the nighttime had a shallow PBLH making concentration accumulated towards the surface. The mountain site, which situates on top of the PBL, can only receive pollutants from the surface (when without horizontal advection), especially when the PBL was fully developed in the midday. Additionally, the NAME model provides pronounced evidence that during the CM period, the mountain site was importantly influenced by the surface emission (the local airmass fraction marked in black in Fig. 2d). This local influence from the same region of surface ground was remarkable during the midday through convective mixing in the PBL, shown in Fig. 1d as the peaked local airmass fraction at 11:00-14:00. The comparable $\mathrm{rBC}$ mass concentration in the midday between surface and mountain suggested an efficient vertical transport of BC (without significant scavenging process within the transport time scale), from the surface to the top of PBL. During the RA period, additional sources from a wider area (besides the local surface emission) also contributed to the mountain, thus having a higher concentration but lower variability for the diurnal pattern.

Similar to BC, CO (Fig. S4a) also showed an efficient upward transport in the midday, leading to enhancement of concentration on the mountain to the same level of surface site. The efficient BC and CO transport means the vertical transport of pollutants had achieved around midday. However, this mechanism did not apply to the overall aerosol ensemble (Fig. 2b). This suggests that the chemically inert species such as $\mathrm{BC}$ and $\mathrm{CO}$ were relatively independent of removal within the time scale of daily vertical transport. A consistent $\mathrm{BC}$ over $\mathrm{CO}$ ratio relative to background $(\triangle \mathrm{BC} / \Delta \mathrm{CO})$ between mountain and surface (Fig. S4c) further confirmed this conclusion. 


\subsection{Less-transported other aerosols}

In contrast with BC mass, the total PM1 had not reached an equivalent level between mountain and surface in the midday, but mountain was $85 \%$ lower than the surface (Fig. 2b). This clearly showed that although BC had been efficiently transported upwards to the top of PBL, the other aerosol masses had not. This led to an enhanced BC mass fraction on the mountain compared to that on the surface (Fig. 2c). Frequency analysis (Fig. 3b) showed that $\mathrm{BC}$ mass fraction was enhanced by $6 \%$ and with a higher frequency at 5-10\%. During RA period when receiving pollutants from a wider region, surface $\mathrm{BC}$ mass fraction had not been largely modified, which may result from strong contributions of local surface sources, thus the surface BC mass fraction could be almost deemed as unaffected by surrounding regions or air mass directions. When the mountain site was perturbed by more aged aerosols from other regions, $\mathrm{BC}$ mass faction was decreased by losing the frequencies of larger values (Fig. 3b).

The decreased BC mass fraction in turn corresponded with an increased SSA by 0.06 throughout the experiment (Fig. 3c, S4h). On the mountain site, as low as SSA550 of 0.80-0.85 was frequently encountered. As Fig. 3e shows, at the same level of PM1, mountain had systematically lower SSA than surface, resulting from the increased BC constitution. The reduced SSA was also observed in some other remote places over the world, e.g. Pistone et al [Pistone et al., 2019] found that reduced SSA for aged biomass burning aerosol from western Africa transported more than 4 days in the free troposphere over the Atlantic Ocean than younger plumes; Nair et al [Nair et al., 2008] showed reduced SSA over the Indian Ocean influenced by continental outflow compared to that along the coast. These studies consistently suggested a less efficient scavenging of $\mathrm{BC}$ than other aerosols, and if the environment is not precursor-rich in forming secondary aerosol, the $\mathrm{BC}$ mass fraction tended to increase, hereby SSA decreased. The reduced SSA means a positive tendency in radiative forcing [Hansen et al., 1981; Haywood and Ramaswamy, 1998; Takemura et al., 2002], thus has important 300 climate implication.

The results using simultaneous measurements of aerosol compositions between both sites (Fig. 3f) showed that around midday, the less upward transported species had more 
semi-volatile characteristics, such as the ammonium nitrate was much lower on the mountain, while the less volatile sulphate particles took a larger portion on the mountain. These less transported particulate masses, as a result of reduced fraction of semi-volatile but only low-volatile or involatile species (such as BC) being efficiently uplifted, which led to that during vertical transport, the initially higher PM1 on the surface had lost some of its mass in particle phase, prevailing the formation of secondary particulate matter on the mountain. A further analysis on the $\Delta \mathrm{PM} / \Delta \mathrm{CO}$ showed persistently lower value at mountain than surface by $0.04 \mu \mathrm{g} \mathrm{m}^{-3} \mathrm{ppb}^{-1}$ during CM (Fig. S4d), indicating a net loss of PM than production. This is in line with the fact that on the surface, a large portion of PM was contributed by secondary semi-volatile particle species due to high emissions of gases close to surface emissions in urban Beijing [Ianniello et al., 2010; Yang et al., 2018; Q Zhang et al., 2014]; whereas during uplift of these species, the pollutants were exposed into a larger air volume and all species were subject to a dilution and evaporation process. This hypothesis depends on the mixing state among the gases and condensed phase, and the partial vapor pressure surrounding the condensed phase should be lower than the equilibrium state of each species at that certain temperature, so that the isothermal evaporation could take place [Neil M Donahue et al., 2006; N. M. Donahue et al., 2011; Simoneit et al., 1993]. We are unable to rule out at which vertical point the repartition had occurred, which requires information of vertical profiles of gas (VOCs) concentrations. Given the much cleaner condition on the mountain, i.e. there was no direct primary sources, after particle being transported to that cleaner environment, the dilution/evaporation process may have already taken effect and to a large extent reduced the semi-volatile components. This mechanism can also be rephrased as a less formation of secondary species in clean environment on the mountain due to lack of gas precursors. Both mechanisms will exert the same impacts on the much-reduced particle phase, but remaining efficiently transported BC.

330 The illustrations above are further supported by the reduced particle size on the mountain (Fig. S4b), also in line with the reduced relative coating thickness of BC by $50 \%$ (Fig. 2e and 3d). This echoes the evaporation process, which reduced the size of 
all particles and the coatings associated with BC. Fig. 3d shows the frequency of BC coating thickness (in $\mathrm{D}_{\mathrm{p}} / \mathrm{D}_{\mathrm{c}}$ ) at 2-3 was missing at the mountain during CM. Previous studies found larger coatings of BC under heavier pollutions [Ding et al., 2019; Dantong Liu et al., 2019a], and here presents the phenomenon in other way around that the coated BC could be stripped out if being exposed under a cleaner environment. The discussions above have excluded the RA period, when regionally transported polluted air masses directly imposed particles with larger size (Fig. S4b) and BC with thicker coatings (Fig. 2e), increasing particle concentrations at both sites.

\subsection{Radiative impacts due to upward transport of BC}

Fig. S6 shows the diurnal variation of vertical profiles of all optical properties measured and derived from the simultaneous measurements between surface and mountain. The vertical gradient index $\left(h_{s}\right)$ reflects the vertical gradient of properties with a larger $h_{s}$ denoting a less negative vertical gradient or fewer difference between mountain and surface. The highest $h_{s}$ values were observed around midday for both absorption and scattering coefficient (Fig. 4a), meaning an efficient upward transport for both BC and other aerosols. The higher $\mathrm{h}_{\mathrm{s}}$ for absorption means a less vertical gradient for absorption than scattering (consistent with Fig. S6a and b) because of the more efficient transport of BC as illustrated above. Mountain consistently showed a lower SSA than surface (Fig. 4b), and the difference between both sites corresponded with the difference on BC mass fraction. The difference on SSA between surface and mountain could cause a positive radiative forcing of up to $5 \mathrm{Wm}^{-2}$ shown in Fig. $4 \mathrm{~b}$ (compared to that without considering lowered SSA at the mountain level).

The efficient upward transport of BC occurred in the midday and coincided with the strongest solar radiation at the time of the day. Additionally, there was higher actinic flux (Fig. 4c) received on the mountain than the surface due to less attenuated solar radiation by aerosol optical depth. This resulted in a considerably enhanced heating rate of $\mathrm{BC}$ on the mountain by both enhanced actinic flux and increased $\mathrm{BC}$ mass concentration. During this time, the heating rate on the mountain matched the level on the surface $(\sim 0.33 \mathrm{~K} /$ Day for both mountain and surface, in Fig. $4 \mathrm{~d})$, corresponding to 
a reduced vertical gradient of heating rate (grey bar of Fig. 4d). The resultant higher heating rate over the top of the PBL, as caused by combined impacts of uplifted BC and higher actinic flux in the midday, could potentially add an enhanced temperature inversion in depressing the PBL development [Z Li et al., 2017]. Previous studies indicated some possibilities for BC in inducing such additional temperature inversion [A J Ding et al., 2016; Ding et al., 2019; Hu et al., 2020; Dantong Liu et al., 2019a] and imposing impacts on pollutant accumulation, and the results here give the evidence that this could occur in a regular diurnal pattern for the anthropogenically polluted PBL.

\section{Conclusion}

This study uses simultaneous measurements between both sites on the surface and over the planetary boundary layer (PBL) respectively, and reveals the efficient upwards transport of $\mathrm{BC}$ in the PBL through daytime convective mixing. This efficient vertical transport however did not apply to other more volatile aerosols. Uplifted aerosols may have experienced stripping process with some more volatile species repartitioned to the gas phase when being transported to a cleaner environment. This led to a higher BC mass fraction over the top of PBL, thus a lower single-scattering albedo.

The observed phenomenon here may have wider application for the remote region influenced by sources rich of $\mathrm{BC}$ constitution, upon where $\mathrm{BC}$ could be transported however not for other substances, given the chemical stability and lower scavenging efficiency of BC. This study showed that at least the polluted PBL influenced by intense anthropogenic emission, may allow an absorbing (but not very scattering) layer to be over the top of the PBL, likely in the midday, exerting heating impacts at this time, potentially disturbing the dynamics of boundary layer. The efficient transport and less scavenging of $\mathrm{BC}$ may lead to enhanced positive radiative effects, for the region being influenced by $\mathrm{BC}$ emission but less concentrated with other substances in the air.

\section{Acknowledgments}

This research was supported by the National Natural Science Foundation of China (41875167) and the National Key Research and Development Program of China 
(2016YFA0602001). We acknowledge the use of the NAME atmospheric dispersion model and associated NWP meteorological data sets made available to us by the Met

395 Office. Part of this work is supported by the National Center of Meteorology, Abu Dhabi, UAE under the UAE Research Program for Rain Enhancement Science.

\section{Data availability statement}

The dataset for this study is openly available at 400 https://data.mendeley.com/datasets/kr7fb26b39/1. 


\section{References}

Bohren, C. F., and D. R. Huffman (2008), Absorption and scattering of light by small particles, John Wiley \& Sons.

Bond, T. C., G. Habib, and R. W. Bergstrom (2006), Limitations in the enhancement of visible light absorption due to mixing state, J. Geophys. Res. - Atmos., 111(D20).

Bond, T. C., et al. (2013), Bounding the role of black carbon in the climate system: A scientific assessment, Journal of Geophysical Research: Atmospheres, 118(11), 5380-5552.

Canagaratna, M. R., et al. (2007), Chemical and microphysical characterization of ambient aerosols with the aerodyne aerosol mass spectrometer, Mass Spectrom Rev, 26(2), 185-222.

410 Cao, G., X. Zhang, and F. Zheng (2006), Inventory of black carbon and organic carbon emissions from China, Atmospheric Environment, 4a34), 6516-6527.

Chen, Y., C. Zhao, Q. Zhang, Z. Deng, M. Huang, and X. Ma (2009), Aircraft study of Mountain Chimney Effect of Beijing, China, Journal of Geophysical Research, 114(D8).

Ding, A., X. Huang, W. Nie, J. Sun, V. M. Kerminen, T. Petaja, H. Su, Y. Cheng, X. Yang, and M. Wang

(2016), Enhanced haze pollution by black carbon in megacities in China, Geophysical Research Letters, 43(6), 2873-2879.

Ding, A. J., et al. (2016), Enhanced haze pollution by black carbon in megacities in China, Geophysical Research Letters, 43(6), 2873-2879.

Ding, S., et al. (2019), Size-Related Physical Properties of Black Carbon in the Lower Atmosphere over Beijing and Europe, Environ Sci Technol, 53(19), 11112-11121.

Donahue, N. M., A. L. Robinson, C. O. Stanier, and S. N. Pandis (2006), Coupled Partitioning, Dilution, and Chemical Aging of Semivolatile Organics, Environmental Science \& Technology, 4Q(8), 2635-2643.

Donahue, N. M., S. A. Epstein, S. N. Pandis, and A. L. Robinson (2011), A two-dimensional volatility basis set: 1. organic-aerosol mixing thermodynamics, Atmospheric Chemistry and Physics, 11(7), 3303-3318.

Emde, C., R. Buras-Schnell, A. Kylling, B. Mayer, J. Gasteiger, U. Hamann, J. Kylling, B. Richter, C. Pause, and T. Dowling (2016), The libRadtran software package for radiative transfer calculations (version 2.0. 1), Geosci. Model Dev., 9(5), 1647-1672.

430 Garratt, J. R. (1994), The atmospheric boundary layer, Earth-Science Reviews, 37(1-2), 89-134.

Guleria, R. P., J. C. Kuniyal, P. P. Dhyani, R. C. Joshi, and N. L. Sharma (2014), Impact of aerosol on surface reaching solar irradiance over Mohal in the northwestern Himalaya, India, Journal of Atmospheric and Solar-Terrestrial Physics, 108, 41-49.

Guo, J., Y. Li, J. B. Cohen, J. Li, D. Chen, H. Xu, L. Liu, J. Yin, K. Hu, and P. Zhai (2019), Shift in the

435 Temporal Trend of Boundary Layer Height in China Using Long-Term (1979-2016) Radiosonde Data, Geophysical Research Letters, 46(11), 6080-6089.

Hansen, J., D. Johnson, A. A. Lacis, S. Lebedeff, P. Lee, D. Rind, and G. L. Russell (1981), Climate Impact of Increasing Atmospheric Carbon Dioxide, Science, 213(4511), 957-966.

Haywood, J. M., and V. Ramaswamy (1998), Global sensitivity studies of the direct radiative forcing

440 due to anthropogenic sulfate and black carbon aerosols, Journal of Geophysical Research, 103, 6043-6058.

Hu, K., D. Zhao, D. Liu, S. Ding, P. Tian, C. Yu, W. Zhou, M. Huang, and D. Ding (2020), Estimating radiative impacts of black carbon associated with mixing state in the lower atmosphere over the northern North China Plain, Chemosphere, 252, 126455.

445 Ianniello, A., F. Spataro, G. Esposito, I. Allegrini, E. Rantica, M. P. Ancora, M. Hu, and T. Zhu (2010), 
Occurrence of gas phase ammonia in the area of Beijing (China), Atmospheric Chemistry and Physics, 10(19), 9487-9503.

Jayne, J. T., D. C. Leard, X. Zhang, P. Davidovits, K. A. Smith, C. E. Kolb, and D. R. Worsnop (2000), Development of an Aerosol Mass Spectrometer for Size and Composition Analysis of Submicron Particles, Aerosol Science and Technology, 33, 49-70.

Jinlong, L. I. (2002), The contribution of anthropogenic hydrocarbons to ozone formation in Beijing areas, China Environmental Science.

Jones, A., D. Thomson, M. Hort, and B. Devenish (2007), The U.K. Met Office's Next-Generation Atmospheric Dispersion Model, NAME III, 580-589.

455 Koch, D., and A. D. D. Genio (2010), Black carbon semi-direct effects on cloud cover: review and synthesis, Atmospheric Chemistry and Physics,10,16(2010-08-18), 103), 7323-7346.

Laborde, M., et al. (2012), Single Particle Soot Photometer intercomparison at the AIDA chamber, Atmos. Meas. Tech., 5(12), 3077-3097.

Li, M., Q. Zhang, J. Kurokawa, J. Woo, K. He, Z. Lu, T. Ohara, Y. Song, D. G. Streets, and G. R. 460 Carmichael (2017), MIX: a mosaic Asian anthropogenic emission inventory under the international collaboration framework of the MICS-Asia and HTAP, Atmospheric Chemistry and Physics, 17(2), 935-963.

Li, Z., J. Guo, A. Ding, H. Liao, J. Liu, Y. Sun, T. Wang, H. Xue, H. Zhang, and B. Zhu (2017), Aerosol and boundary-layer interactions and impact on air quality, National Science Review, 4(6), 810-833.

465 Liu, D., D. Zhao, Z. Xie, C. Yu, Y. Chen, P. Tian, S. Ding, K. Hu, D. Lowe, and Q. Liu (2019a), Enhanced heating rate of black carbon above the planetary boundary layer over megacities in summertime, Environmental Research Letters, 14(12), 124003.

Liu, D., et al. (2014), Size distribution, mixing state and source apportionment of black carbon aerosol in London during wintertime, Atmos. Chem. Phys., 14(18), 10061-10084.

470 Liu, D., et al. (2019b), Contrasting physical properties of black carbon in urban Beijing between winter and summer, Atmospheric Chemistry and Physics, 19(10), 6749-6769.

Liu, D., et al. (2017), Black-carbon absorption enhancement in the atmosphere determined by particle mixing state, Nat. Geosci., 10(3), 184-188.

Liu, P., C. Zhao, P. Liu, Z. Deng, M. Huang, X. Ma, and X. Tie (2009), Aircraft study of aerosol vertical

475 distributions over Beijing and their optical properties, Tellus Series B-chemical \& Physical Meteorology, 61(5), 756-767.

Middlebrook, A. M., R. Bahreini, J. L. Jimenez, and M. R. Canagaratna (2012), Evaluation of Composition-Dependent Collection Efficiencies for the Aerodyne Aerosol Mass Spectrometer using Field Data, Aerosol Science and Technology, 46(3), 258-271.

480 Nair, V. S., S. Suresh Babu, and K. Krishna Moorthy (2008), Spatial distribution and spectral characteristics of aerosol single scattering albedo over the Bay of Bengal inferred from shipborne measurements, Geophysical Research Letters, 35(10).

Pistone, K., et al. (2019), Intercomparison of biomass burning aerosol optical properties from in situ and remote-sensing instruments in ORACLES-2016, Atmospheric Chemistry and Physics, 485 19(14), 9181-9208.

Ramanathan, V., and G. Carmichael (2008), Global and regional climate changes due to black carbon, Nature Geoscience, 36(1), págs. 335-358.

Simoneit, B. R. T., W. F. Rogge, M. A. Mazurek, L. J. Standley, and G. R. Cass (1993), Lignin Pyrolysis Products, Lignans, and Resin Acids as Specific Tracers of Plant Classes in Emissions from Biomass

490 Combustion, Environ.sci.technol, 27(12).

Srivastava, A., K. Ram, P. Pant, P. Hegde, and H. Joshi (2012), Black carbon aerosols over Manora 
Peak in the Indian Himalayan foothills: implications for climate forcing, Environmental Research Letters, 7(1), 014002.

Streets, D. G., J. S. Fu, C. J. Jang, J. Hao, K. He, X. Tang, Y. Zhang, Z. Wang, Z. Li, and Z. Qiang (2007), Air quality during the 2008 Beijing Olympic Games, Atmospheric Environment, 41(3), 480-492.

Takemura, T., T. Nakajima, O. Dubovik, B. N. Holben, and S. Kinne (2002), Single-Scattering Albedo and Radiative Forcing of Various Aerosol Species with a Global Three-Dimensional Model, Journal of Climate, 15(4), 333-352.

Taylor, J., J. Allan, D. Liu, M. Flynn, R. Weber, X. Zhang, B. Lefer, N. Grossberg, J. Flynn, and H. Coe (2015), Assessment of the sensitivity of core/shell parameters derived using the single-particle soot photometer to density and refractive index, Atmos. Meas. Tech., 8(4), 1701-1718.

Tian, P., D. Liu, M. Huang, Q. Liu, D. Zhao, L. Ran, Z. Z. Deng, Y. Wu, S. Fu, and K. Bi (2019), The evolution of an aerosol event observed from aircraft in Beijing: An insight into regional pollution transport, Atmospheric Environment, 206, 11-20.

505 Yang, W., J. Li, M. Wang, Y. Sun, and Z. Wang (2018), A Case Study of Investigating Secondary Organic Aerosol Formation Pathways in Beijing using an Observation-based SOA Box Model, Aerosol and Air Quality Research, 18(7), 1606-1616.

Zhang, Q., B. Yuan, M. Shao, X. Wang, S. Lu, K. Lu, M. Wang, L. Chen, C. C. Chang, and S. C. Liu (2014), Variations of ground-level O3 and its precursors in Beijing in summertime between 2005 510 and 2011, Atmospheric Chemistry and Physics, 14(12), 6089-6101.

Zhang, Y., Y. Li, J. Guo, Y. Wang, and H. Chen (2019), The climatology and trend of black carbon in China from 12-year ground observations, Climate Dynamics(18).

Zhao, D., D. Liu, C. Yu, P. Tian, D. Hu, W. Zhou, S. Ding, K. Hu, Z. Sun, and M. Huang (2020), Vertical evolution of black carbon characteristics and heating rate during a haze event in Beijing winter,

515 Science of The Total Environment, 709, 136251.

Zhao, D., et al. (2019), Vertical characteristics of black carbon physical properties over Beijing region in warm and cold seasons, Atmospheric Environment, 213, 296-310. 